\title{
HIV INFECTIONS AND AIDS: CONTINUOUS VIGILANCE NEEDED TO CONTAIN THE EPIDEMIC
}

\author{
Editorial team (eurosurveillance@ecdc.europa.eu) ${ }^{1}$ \\ 1. Eurosurveillance, European Centre for Disease Prevention and Control, Stockholm, Sweden
}

The 1 December, known as World AIDS Day since 1988, provides an occasion to raise awareness and take stock of the latest developments in the human immunodeficiency virus (HIV)/acquired immunodeficiency syndrome (AIDS) epidemic. Since it was first recognised in the early 1980s, this epidemic has been associated with high morbidity and mortality. UNAIDS, the Joint United Nations Programme on HIV/AIDS, estimates that in 2007 alone two million people have died of AIDS worldwide, of whom around 270,000 are children under 15 years of age [1]. An additional 33 million people are living with HIV globally; the estimated number of new HIV cases in 2007 was 2.7 million. These figures clearly demonstrate that HIV/AIDS remains a major challenge to public health; therefore measures to contain the epidemic are of paramount importance.

World AIDS Day is an opportunity to shed light on the many activities and initiatives that are being conducted at national and international levels to fight the spread of the disease. From its beginning in late 1995 until now, Eurosurveillance has focussed extensively on HIV/AIDS. The journal has closely monitored the epidemic primarily in Europe but has also reported on worldwide trends. The first publication on HIV/AIDS in March 1996 by F. Cazein et al. entitled Prevalence of HIV-2 infection in Europe [2] was followed by regular annual updates on the situation, and over the years we have covered a wide range of associated aspects of the infection and their impact on public health, such as therapeutic advances including post-exposure prophylaxis, novel testing methods, behavioural factors and prevention measures. In September 2008, a special issue was dedicated to the widespread advances made in Europe in estimating the real number of newly acquired HIV infections based on STARHS (Serological Testing Algorithms for Recent HIV Seroconversion) assays [3]. Next week's issue of the journal will include short communications providing an epidemiological update on the HIV/AIDS situation in Europe while analysing the latest figures on HIV/AIDS surveillance in the WHO European Region, highlighting the situation in intravenous drug users in Europe and reporting on the continuing HIV and other sexually transmitted infection epidemics in the United Kingdom.

The driving forces of the HIV/AIDS epidemic are manifold and transmission patterns vary geographically. In the European Union (EU), the predominant transmission mode remains unsafe sex between men, whereas reported heterosexual transmission is in part attributed to persons from high-prevalence countries outside the EU. In eastern Europe and the Baltic States an important driver of the epidemic is intravenous drug use $[4,5]$. To stop the spread of the disease it is crucial to have a thorough knowledge of the transmission routes and of other factors contributing to the epidemic as well as to ensure access to testing, treatment and care for all.
Furthermore, campaigns are needed to raise awareness of the risk of contracting infection and of the possible preventive measures. If such campaigns are to reach their target audiences, they must be tailored to the existing knowledge, attitudes and behaviour in the general population as well as in specific populations at risk. In this issue of Eurosurveillance an article by S.A. Cowan and J. Haff reports on the results of a survey conducted in Denmark in 2006 on HIV and risk behaviour among men who have sex with men (MSM) [6]. The results show that in this group in Denmark, the numbers of sex partners and unsafe sex practices are increasing compared to those of three earlier surveys conducted since 2000. A total of $33 \%$ of the respondents had practised unsafe sex, defined as unprotected anal intercourse with one or more partners of different or unknown HIV status. The number of partners was the strongest predictor of unsafe sex; the probability of having had unsafe sex ranged from $17 \%$ in men with one partner to $58 \%$ in men with more than 20 partners. HIV status was also a strong predictor; in a bivariate analysis, $49 \%$ of HIV-positive men had practised unsafe sex compared to $25 \%$ of HIV-negative men. The results of this survey demonstrate a clear need to respond to such ongoing risky behaviour in MSM and should be compared with the findings of similar studies in other countries in Europe and taken into consideration when designing targeted prevention campaigns in the future.

\section{References}

1. Joint United Nations Programme on HIV/AIDS (UNAIDS), 2008 Report on the global AIDS epidemic. UNAIDS, Geneva, August 2008. Available from: http:// www.unaids.org/en/KnowledgeCentre/HIVData/GlobalReport/2008/2008_Global_ report.asp

2. Cazein F, Hamers FF, Alix J, Brunet JB. Prevalence of HIV-2 infection in Europe. Euro Surveill 1996;1(3):pii=196. Available from: http://www.eurosurveillance. org/ViewArticle.aspx?ArticleId=196

3. Barin F, Nardone A. Monitoring HIV epidemiology using assays for recent infection: where are we?. Euro Surveill 2008;13(36):pii=18967. Available from: http://www.eurosurveillance.org/ViewArticle.aspx?ArticleId =18967

4. Hamers FF, Devaux I, Alix J, Nardone A. HIV/AIDS in Europe: trends and EU-wide priorities. Euro Surveill 2006;11(47):pii=3083. Available from: http://www. eurosurveillance.org/ViewArticle.aspx?ArticleId=3083

5. Hamers FF, Downs AM. HIV in central and eastern Europe. Lancet. 2003 31;361(9372):1910-1.

6. Cowan SA, Haff J. HIV and risk behaviour among men who have sex with men in Denmark - the 2006 Sex Life Survey. Euro Surveill. 2008;13(48):pij=19050. Available from: http://www.eurosurveillance.org/ViewArticle.aspx?ArticleId=19050.

This article was published on 27 November 2008.

Citation style for this article: Editorial team. HIV infections and AIDS: continuous vigilance needed to contain the epidemic. Euro Surveill. 2008;13(48):pii=19047. Available online: http://www.eurosurveillance.org/ViewArticle.aspx?ArticleId=19047 